\title{
Ethical challenges in fetal surgery
}

\author{
Anna Smajdor
}

\section{Correspondence to}

Dr Anna Smajdor, School of Medicine, Health Policy and Practice, University of East Anglia, Norwich NR4 7TJ, UK; a.smajdor@uea.ac.uk

Received 5 August 2010 Accepted 17 September 2010 Published Online First 11 November 2010

\section{(8) UNLOCK:1}

This paper is freely available online under the BMJ Journals unlocked scheme, see http:// jme.bmj.com/site/about/ unlocked.xhtml

\section{ABSTRACT}

Fetal surgery has been practised for some decades now. However, it remains a highly complex area, both medically and ethically. This paper shows how the routine use of ultrasound has been a catalyst for fetal surgery, in creating new needs and new incentives for intervention. Some of the needs met by fetal surgery are those of parents and clinicians who experience stress while waiting for the birth of a fetus with known anomalies. The paper suggests that the role of technology and visualisation techniques in creating and meeting such new needs is ethically problematic. It then addresses the idea that fetal surgery should be restricted to interventions that are life-saving for the fetus, arguing that this restriction is unduly paternalistic. Fetal surgery poses challenges for an autonomy-based system of ethics. However, it is risky to circumvent these challenges by restricting the choices open to pregnant women, even when these choices appear excessively altruistic.

Fetal surgery was pioneered in the 1980s by Dr Michael Harrison 'the father of fetal surgery' at the University of San Francisco, California Children's Hospital. ${ }^{1}{ }^{2}$ Since Harrison began his work, others have taken up the challenge, and fetal treatment centres are now in operation in Philadelphia, Boston, Cincinnati and Texas to name just a few. Fetal surgery has also become a reality in the UK. Figures given by Lord Darzi in a recent parliamentary debate indicate that 192 operations were performed on fetuses in the UK between 2006 and $2007 .^{3}$

Fetal surgery can be carried out with varying degrees of invasiveness. Open surgery involves making an incision in the mother's abdomen and lifting out the uterus. An incision is then made in the uterus to expose as much of the fetus as is necessary to perform the surgery. The fetus remains connected to the placenta throughout the procedure. When surgery is completed, the fetus is returned to the uterus, the incision is sutured, the uterus is replaced in the abdomen, and the abdominal incision is closed.

Other less invasive options include endoscopic techniques and percutaneous procedures. Doyal and Ward, ${ }^{4}$ writing on this subject in 1998, suggested that the endoscopic and percutaneous approaches would be likely to supplant the more invasive open fetal surgery. However, to date this has not been the case. All types of fetal surgery are still being practised and advertised in the various US centres listed above.

There are two primary ethical issues that I want to explore in this context. One is the transition from imaging to intervention. While ultrasound is a non-invasive method of visualising a fetus, its routine use as a method of 'reassuring' pregnant women has in fact been a catalyst for the development of fetal surgery. ${ }^{5}$ This calls into question the apparently neutral status of imaging technologies. It also requires a consideration of the harms and benefits of interventions that result from the development of such technologies.

The second issue I will discuss is the way that fetal surgery challenges autonomy-focussed approaches to medical ethics. Doyal and Ward ${ }^{4}$ suggest that women's autonomy may be threatened if fetuses are regarded as patients in their own right. Yet they, and a number of clinicians, suggest restricting access to fetal surgery on paternalistic grounds, which also present a threat to women's autonomy.

\section{IMAGING LEADS TO INTERVENTION}

In the past, mothers and clinicians spent the 9 months of pregnancy in more or less blissful ignorance of what was happening inside the womb. The development of ultrasound has dramatically altered this. Ultrasound was first used in obstetrics in the late 1950s, and it quickly became apparent that it could be used to track an entire pregnancy. There was an upsurge in the use of the technique, and it has now become part of the routine management of pregnancy. ${ }^{6}$

Initially, ultrasound simply provided a basic image of the fetus, allowing clinicians to identify, for example, whether it was in the breach position. However, as techniques became more sophisticated, a range of diagnostic possibilities emerged. Visualising a fetus may reveal its gender, whether it is likely to have Down syndrome, and whether the umbilical cord is threatening its circulation. Is this a change for the better? Ultrasound is often described as offering reassurance to mothers, but this is likely to be the case only if the fetus is deemed normal. It is precisely because ultrasound has the capacity to identify abnormalities that it is used in medicine. 78

As soon as it becomes feasible to identify anomalies at the prenatal stage, questions are raised about what can and what should be done. The urge to intervene is a natural corollary of the ability to present a problem in a way that preserves its visual immediacy. People feel differently about things they can see from the way they feel about things they merely know.9 10 Feeling differently means that one is likely to act differently. A powerful example of this is the Ethiopian famine in the 1980s, and the UK's response to it. Many people in the UK knew that people were starving in Ethiopia. But when pictures of the famine were aired, when the suffering of the people who we had previously known about only in the abstract, became visible, 
there was a sudden upsurge in public response. As we could see, we now felt obliged to act. ${ }^{11} 12$

Ultrasound technology has made the fetus visible and created a corresponding urge to intervene. It is for this reason that it is important to recognise the connection between fetal surgery and ultrasound, but also the more general connection between the acquisition of data and the compulsion to act on that data. So although an imaging technology may in isolation be a non-invasive means of observation, it may become part of a technological process that results in increased interventions. The question then to be asked is whether this systematic process of increased surveillance, diagnosis and intervention is beneficial, and if so, to whom?

\section{WHO BENEFITS FROM FETAL SURGERY?}

The most obvious beneficiaries of fetal surgery are the fetuses that are diagnosed and treated in utero, and I will discuss this shortly. However, it is important to note that fetal surgery may also serve the interests of people other than the fetus. Parents and clinicians may have something to gain from fetal interventions. It could be argued that these benefits are vicariousthat clinicians and parents benefit only insofar as the fetus does. However, there are additional ways in which parents and clinicians may benefit, which are not simply derived from the effects on the fetus. Doyal and Ward ${ }^{4}$ note the advantages that may accrue to clinicians who make a name for themselves in this pioneering area. Careers can be made and reputations built. There is not scope in this paper to explore the ethics of professional self-interest in this context, but Doyal and Ward ${ }^{4}$ are certainly right to identify the existence of such interests.

Benefits to parents and clinicians may also be derived from the fact that surgery offers a course of action-doing, rather than simply waiting. As I have suggested, it may be difficult to maintain a non-interventionist attitude to problems that have been identified, especially if they have been made visible. Having to wait for the birth before intervening is frustrating. There is evidence to suggest that acting is psychologically easier than simply waiting in a number of contexts. Interestingly, this is true regardless of how successful the act may be. For example, among patients waiting for heart surgery, the waiting itself is a significant cause of psychological distress, independently of any symptom-based factors or specific fears of outcomes being worsened by the passage of time. Rather, it is the waiting in and of itself that is psychologically harmful. ${ }^{13} 14$

Of course, it might be argued that patients awaiting surgery are likely to be anxious anyway. The looming prospect of surgery together with the existence of a known medical problem may be stressful. Prospective parents, on the other hand, may be apprehensive about what the future holds, but are not necessarily ill themselves. Therefore, it might be thought that the analogy does not hold, and that the anxiety experienced by patients waiting for treatment is linked specifically with their underlying medical condition. However, research indicates that waiting for surgery for someone else is also highly psychologically distressing, for example in the case of spouses of patients with heart problems, ${ }^{15}$ and also in the case of men whose partners are waiting for in-vitro fertilisation treatment. ${ }^{16}$ The stress of waiting for treatment is not specifically linked to the person who has the illness, but is shared between all those who may be affected by the outcome of the anticipated event.

The psychological difficulty of waiting for the birth of a fetus with known medical problems is a source of distress to parents-and health professionals too. Turning this around, regardless of whether fetal surgery benefits the fetus, it may provide a means of resolving the psychological stress caused by the anxiety of waiting until the birth. This raises some interesting ethical issues. I have argued that the psychological distress of parents and clinicians partly constitutes the 'need' for intervention, but this need in itself is derived from the routine use of the diagnostic technology. That is to say, the use of ultrasound creates new needs that it, in turn, provides the means of fulfilling. If parents and clinicians did not see the images, their need for the psychological comfort of surgical intervention would not arise.

It is often assumed that medical progress and the development of new medical technologies necessarily serve to reduce the sum of human need, but there is another way of looking at this: technology identifies new problems, which in turn generate new needs that must be met through further developments in medical technology. According to bioethicist Daniel Callahan, ${ }^{17}$ this constitutes an ongoing cycle, or arms race. He believes that this endless push towards further technologies and interventions places a strain on resources that may ultimately serve to increase suffering rather than diminish it.

I would suggest that Callahan ${ }^{17}$ is right to recognise the role of new technologies in creating new medical needs. Fetal surgery is a medical intervention whose function is, at least partly, to relieve the psychological stress that adverse ultrasound findings cause to parents and clinicians. Once the technology has been developed, however, it is very hard to suggest that it should be disregarded, or that the individuals who might seek to use it should be prevented from doing so. For this reason, I will not go further into Callahan's argument here. In the next section, I will focus on the ethical management of fetal surgery in the context of individuals who may be directly affected by it.

\section{BENEFITS FOR THE FETUS AND RISKS FOR MOTHERS}

The motivations for fetal surgery that I have discussed above apply to parents and clinicians, but what are the advantages, if any, for the fetus in being operated upon while still in utero?

There are some medical problems that, without surgery, will almost inevitably cause the death of the fetus before, or shortly after, birth. Among the conditions that might fall into this category are congenital diaphragmatic hernia, in which the abdominal organs protrude into the chest, impeding lung development. ${ }^{18}$ Teratomas that develop at the base of the coccyx are also highly risky for fetuses, as they can grow so large as to place a strain on the heart. When this has happened, surgery may be the only way of preserving the life of the fetus. ${ }^{19}$

These benefits come at a cost to the mother. Open fetal surgery involves two Caesarean sections for the woman-the first at the time of the fetal intervention, the second at the time the baby is born. There is a risk of rupturing the uterus. Mothers will need to spend 5-7 days in hospital. ${ }^{20}$ Any future children will have to be delivered by Caesarean. Open fetal surgery very frequently involves premature labour and delivery-on average babies are born approximately 8 weeks after surgery. Mean gestational age at delivery according to one study was 32.5 weeks. $^{20}$ The risks of endoscopic and percutaneous procedures are lower, but still significant.

Doyal and Ward ${ }^{4}$ argue that only the most serious conditions can justify fetal surgery. A similar stance is adopted by many of the clinicians involved in this kind of surgery. The risks imposed on women whose fetuses undergo surgery are thought to be justified only if the life of the fetus is in danger. This might seem to offer a relatively straightforward ethical blueprint for the management of fetal surgery. Other conditions-non-lethal tumours, for example, or cleft palate-could be addressed after 
the birth of the child without going through the mother, as it were. However, if we are to countenance fetal surgery at all, why should we restrict it to conditions that are life-threatening to the fetus? The obvious answer is: to protect mothers. Women should not have to undergo surgery unless it is absolutely necessary.

Yet who should be charged with making this judgement as to whether the risks to women are acceptable in balance against the benefits to the fetus? Should it be women themselves, or their clinicians? There are in fact some persuasive arguments in favour of fetal surgery for non-life-threatening conditions. If a problem has been identified by ultrasound, fetal surgery may offer the possibility of remedying the condition there and then without the need for postnatal intervention. Giving birth to a healthy child and taking it home straight away might seem more appealing than having a birth followed by surgery and uncertainty.

Still more significantly, the uterine environment promotes quicker healing with less scar tissue. Women may be eager to secure this benefit for their child even if its life is not at risk. When defects such as cleft palate or teratoma have been diagnosed prenatally, scarless fetal surgery will be a major advantage over postnatal treatment. It is plausible that some patients might want to spare their offspring the risk of disfiguring scars. This raises the question of whether the adult's willingness to undergo such procedures is sufficient justification to undertake them. It may be difficult to define the circumstances under which fetal surgery can take place without lapsing into paternalism: restricting patients' options for their own benefit, against their wishes.

\section{MATERNAL ALTRUISM AND INFORMED CONSENT}

Is it ethically acceptable to impose the risks of surgery on someone who stands to derive no clinical benefit? Surely a large part of the answer depends on the ability to consent. A variation of this question has been explored by Paris and Harris ${ }^{21}$ in the context of operating on a twin in utero. Both twins are exposed to the risks of surgery. Therefore, they argue that both become patients. However, the healthy twin's interests are not served by being exposed to the risks of surgery. For this reason, they conclude that it would be unethical for doctors to operate in such circumstances. Seemingly, this argument could also apply to the mother of the fetus(es). In fetal surgery, mother and fetus become patients, and their interests might also seem to conflict in a similar way. Yet Paris and Harris ${ }^{21}$ do not rule out fetal surgery entirely, only in circumstances in which a healthy twin may be put at risk.

The difference here is that the mother has the ability to consent to the intervention, whereas the healthy twin does not, but Harris and Paris ${ }^{21}$ recognition of fetuses as patients in their own right seems to raise some problems. Could a fetal patient's interests outweigh those of its mother? If so, women's autonomy and bodily integrity might be threatened by the development of fetal surgery. Doyal and Ward ${ }^{4}$ discuss the risk of coercion in this context, arguing that women's autonomy should be regarded as paramount, and surgery should only ever be performed with the mother's informed consent. The legal and moral status of the fetus, in their analysis, is kept within very restricted parameters - it may be 'special', but its interests are explicitly and necessarily subordinate to those of the mother.

Just as fetal surgery stretches the notion of what constitutes a patient, so the concept of informed consent seems to have become strangely distorted in this context. According to at least one practitioner: 'There will be very few patients for whom it is an appropriate intervention [...] We are going to deal with the unusual patient who can give an informed consent [...] These patients are women who are carrying fetuses with life-threatening conditions. ${ }^{22}$ Here, in a strange inversion of what one might normally understand by the term, informed consent is deemed valid not by virtue of the wishes and understanding of the patient, but by virtue of the condition experienced by the fetus. Similarly odd ideas about consent and patient choice are implicit in the following quote: 'The key to choosing appropriate patients for fetal intervention is to identify those that would not survive with postnatal therapy alone. ${ }^{23}$ Here again, it is not the mother who chooses whether to undergo the treatment. Rather, the medical establishment chooses her as an acceptable vehicle through which the treatment can be offered. It is no longer clear here just what role informed consent and respect for autonomy are playing in this undoubtedly complex ethical situation.

Although Doyal and Ward ${ }^{4}$ take the mother's consent to be of fundamental importance, they too make some problematic assumptions. Given the high rate of failure for open fetal surgery in its early days, they suggest that the women involved must have been inadequately informed. The implication here is that there are some risks that no one would consent to if fully informed, but this does not harmonise with what is known about decisions related to reproduction and fertility. It has been repeatedly shown that fertility patients are willing to undergo procedures that they know to be highly unlikely to succeed and that are risky and highly expensive. Women in this context frequently describe themselves as having had 'no choice'. In an article published in the Sunday Times, a woman who underwent fetal surgery in the UK says 'The only option for me was to have the surgery'. ${ }^{24}$

This language of compulsion is not easily assimilated into conventional ethical frameworks centred on autonomy and choice. This does not mean that women have been misinformed, as Doyal and Ward ${ }^{4}$ assume. It means that decisions made in such situations are not based on self-protection or risk avoidance. Even if the risks of fetal surgery were still greater, the benefits more marginal, and women had access to every possible relevant fact and statistic, they might still be willing to undergo fetal surgery. Crucially, pregnant women's altruism is not necessarily or ordinarily limited to life-saving interventions. Most of the sacrifices that pregnant women make are designed give the child the best start possible, rather than save its life per se. There are conditions for which fetal surgery might offer relatively modest benefits (eg, reduced scarring) but a woman may still wish to confer these benefits on her child.

Our society expects and demands that pregnant women and mothers should be altruistic. ${ }^{25}$ Pregnancy itself is commonly regarded as a state in which what would normally be supererogatory becomes morally required. ${ }^{26}$ Pregnant women often behave in ways that in any other context would be deemed clearly supererogatory-perhaps even pathologically so. I have argued elsewhere that the demands placed on mothers and pregnant women are unreasonable and excessive. ${ }^{27}$ It is because of this that fetal surgery makes us uneasy, I would suggest. Expectations of maternal sacrifice in conjunction with new technological means of intervention have led us to an uncomfortable place.

How should we relieve this discomfort? The accepted view seems to be that we should erect a variety of barriers that constrain women's options within parameters that others have deemed reasonable. In short, a reversion to paternalism: it cannot be safely left to pregnant women to decide. This perpetuates and reinforces the idea that pregnant women are so 
extravagantly altruistic that their choices must be restricted in their own interests. In essence, because our ideas of maternal altruism do not fit into an autonomy-based ethics system, we are tempted to exclude pregnant women from their place in that system by a system of paternalistic restrictions. The paternalistic nature of these restrictions is often masked by their apparently clinical rationale. Laura Purdy ${ }^{28}$ has demonstrated the level to which paternalistic assumptions infiltrate arguments related to selective reduction-another facet of fetal surgery.

Perhaps this encroachment of paternalism is a subversion of medical ethics on a greater scale than the problem that it is attempting to solve. A better approach might be to look to the social world in which women's freedom to make choices is formed. It is a mistake here to suppose that non-pregnant women, and men, are perfectly free in their choices and decisions. Informed consent is always and necessarily constrained by social expectations and values. It is always likely to be imperfect, but if we feel that social pressures are coming to bear too heavily on a particular area of decision-making, there may be an opportunity to reconsider and question that social pressure, rather than hastening towards the refuge of paternalism.

The spectacle of a woman undergoing open fetal surgery is undoubtedly disturbing. It illustrates in the most graphic way the collision of two highly problematical assumptions: first, that ever-greater surveillance of pregnancy is beneficial, or at least not harmful, and second, that pregnant women should sacrifice their bodily integrity for the welfare of their child.

Competing interests None declared.

Provenance and peer review Not commissioned; externally peer reviewed.

\section{REFERENCES}

1. University of California, San Francisco. 2009. Michael R. Harris MD - The Full Story. http://www.fetus.ucsfmedicalcenter.org/our_team/harrison_bio.asp (Accessed July 2010).

2. Bianchi D, Crombleholme T, D'Alton M. Fetology: diagnosis and management of the fetal patient. New York: McGraw-Hill, 2000:pxiii.

3. HC Deb. 2008;699:cWA16. http://www.parliament.the-stationery-office.com/pa/ Id200708/ldhansrd/text/80218w0003.htm\#08021815000026 (accessed July 2010).

4. Doyal L, Ward C. Fetal surgery: ethical and legal issues. Semin Neonatol 1998:3:255-65

5. Kumar S, O'Brien A. Recent developments in fetal medicine. BMJ 2004;328:1002-6.
6. Gottesfeld KR. Quoted in McNay M, Fleming J. 40 Years of obstetric ultrasound 1957-1997. Ultrasound Med Biol 1999;25:3-56.

7. Rothman BK. The tentative pregnancy: prenatal diagnosis and the future of motherhood. London: Unwin and Hyman, 1988.

8. Taylor JS. Image of contradiction: obstetrical ultrasound in American culture. In: Franklin S, Ragoné H, eds. Reproducing reproduction: kinship, power, and technological innovation. Philadelphia: University of Pennsylvania Press, 1998

9. Kirklin D. The role of medical imaging in the abortion debate. J Med Ethics 2004;30:426.

10. Jackson E. Regulating reproduction: law, technology and autonomy. Oxford: Hart, 2001:121.

11. Minear L, Scott C, Thomas G, et al. The news media, civil war and humanitarian action. Lynne Rienner Publishers, 1996:2.

12. Philo G. From Buerk to Band Aid. The media and the 1984 Ethiopian famine. In: Eldridge J, ed. Getting the message: news truth and power. London: Routledge, 1993.

13. Zipfel S, Lowe B, Paschke T, et al. Psychological distress in patients awaiting heart transplantation. J Psychosom Res 1998;45:465-70.

14. Osuna EE. The psychological cost of waiting. J Math Psychol 1985;29:82-105.

15. Staples $\mathbf{P}$, Jeffrey J. Quality of life, hope and uncertainty of cardiac patients and their spouses before coronary artery bypass surgery. Can $\mathrm{J}$ Cardiovasc Nurs 1997;8:7-16

16. Tarabusi M, Volpe A, Facchinetti F. Psychological group support attenuates distress of waiting in couples scheduled for assisted reproduction. J Psychosom Obstet Gynecol 2004;25:273-9.

17. Callahan D. What kind of life: the limits of medical progress. New York: Simon and Schuster, 1990

18. Deprest JA, Hyett JA, Flake AW, et al. Current controversies in prenatal diagnosis 4: should fetal surgery be done in all cases of severe diaphragmatic hernia? Prenat Diagn 2009;29:15-19.

19. Grethel EJ, Wagner AJ, Clifton MS, et al. Fetal intervention for mass lesions and hydrops improves outcome: a 15-year experience. J Pediatr Surg 2007:42:117-23

20. Kitano Y, Flake AW, Crombleholme TM, et al. Open fetal surgery for life-threatening fetal malformations. Semin Perinatol 1999:23:448-61.

21. Paris JJ, Harris MC. Ethical issues in fetal surgery involving a twin pregnancy. J Women's Health Gend-Based Med 2001;10:525-31.

22. Nancy Chescheir, director of foetal therapy programme, University of North Carolina. Quote in Agnew T. Before their time. New Scientist 2000. http://www.newscientist. com/article/mg16622372.400-before-their-time.html.

23. Cass D. Fetal surgery for congenital diaphragmatic hernia: the North American experience. Semin Perinatol 2005;29:104-11.

24. Templeton SK. Emergency ward womb: how surgeons save the unborn. The Sunday Times, 2006. http://www.timesonline.co.uk/tol/news/article664546.ece.

25. Oakley A. Essays on women, medicine and health. Edinburgh: Edinburgh University Press, 1993:84.

26. Mullin A. Reconceiving pregnancy and childcare: ethics, experience, and reproductive Labor. Cambridge: Cambridge University Press, 2005.

27. Smajdor A. Between fecklessness and selfishness: is there a biologically optimal time for motherhood? A reply to Daniel Callahan. In: Simonstein F, ed. Reprogen-ethics and the future of gender. Dordrecht: Springer, 2009:105-17.

28. Purdy L. Women's reproductive autonomy: medicalisation and beyond. J Med Ethics 2006; 32:287-91 